\section{Late replication studies and esterase D levels in a case of unbalanced $\mathrm{X}$; autosome translocation, $46, X, t(X ; 13)(q 27 ; q 12)$}

The proband is a three year old Maori girl born to a 17 year old mother and a 20 year old father. Pregnancy was uneventful with forceps delivery at term. Birth weight was 3340 g. No external abnormality was observed other than one extra digit on each foot which was ligated before discharge. At the age of three years her height is $98.0 \mathrm{~cm}$ and weight $16 \mathrm{~kg}$. She has been assessed as mildly mentally re-

Keceived for publication 10 November 1987 Accepted for publication 13 November 1987. tarded, functioning perceptually and cognitively at around the two year level. Her gross motor skills are significantly delayed (16 month level). She has poor equilibrium reactions in standing, runs clumsily, cannot jump, but manages steps. Expressive and receptive language is up to the 20 month level. Self care skills, emotional, and social $N$ behaviour are at the two year level. Hair and skull are normal. Her vision is good with a moderately high degree of astigmatism. She has a wide nasal bridge which is not inconsistent with her race. Her mouth, dentition, palate, and mucosa are normal. Her ears have attached lobes but $\subseteq$ are otherwise normal (fig 1a). The fingers are spindly with clinodactyly of the fifth finger (fig 1b). Her feet are normal with a minor degree of overlapping of the second and third toes. External genitalia, circulatory system, and chest $x$ ray showed no abnormalities. Cytogenetic studies showed a complement of $46, X, \operatorname{der}(X), t(X ; 13)(X p t e r \rightarrow X q 27:: 13 q 12$ $\rightarrow 13 q$ ter) in all 200 cells analysed (fig $2 \mathrm{a}$ ).

BrdU replication studies show the $X$ portion of the $\operatorname{der}(\mathrm{X})$ to be late replicating in all cells. The $13 \mathrm{q}$ portion in
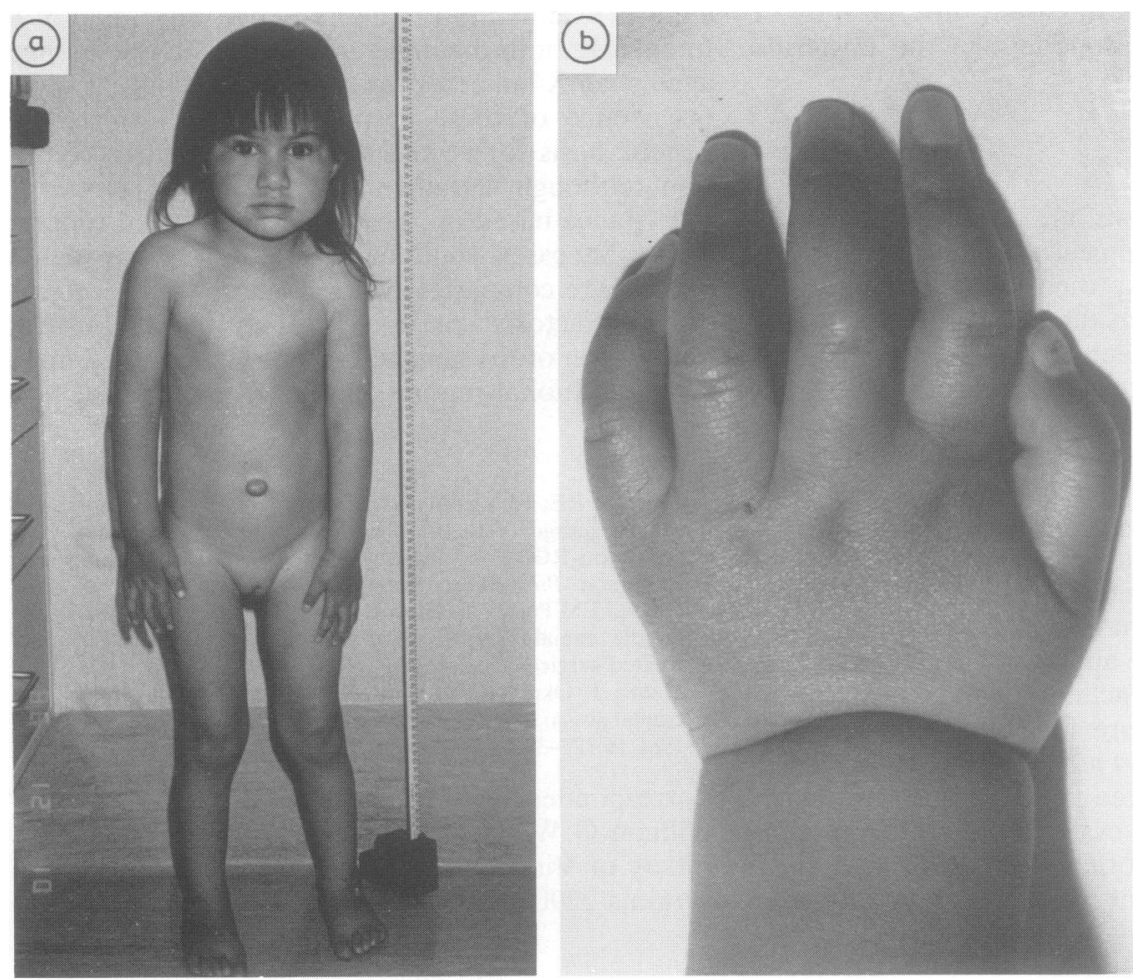

FIG 1 (a) Front view of index case. (b) Dorsal view of left hand of index case showing spindle shaped fingers and clinodactyly of the fifth finger. 
the $\operatorname{der}(\mathrm{X})$ has a staining pattern comparable to the two normal chromosomes 13 , with the exception of band $13 q 22$ which is either faintly stained, as in a to e of fig $2 b$, or not visible at all. Parental chromosomes were normal. Electrophoresis of ESD showed the patient and her parents to be type 1-1. Measurements of the level of red blood cell ESD in the patient showed an activity of 99.7 units compared to the maternal and paternal activities, which were 59.8 and $77 \cdot 3$ units respectively.

This case is another example of discontinuous spreading
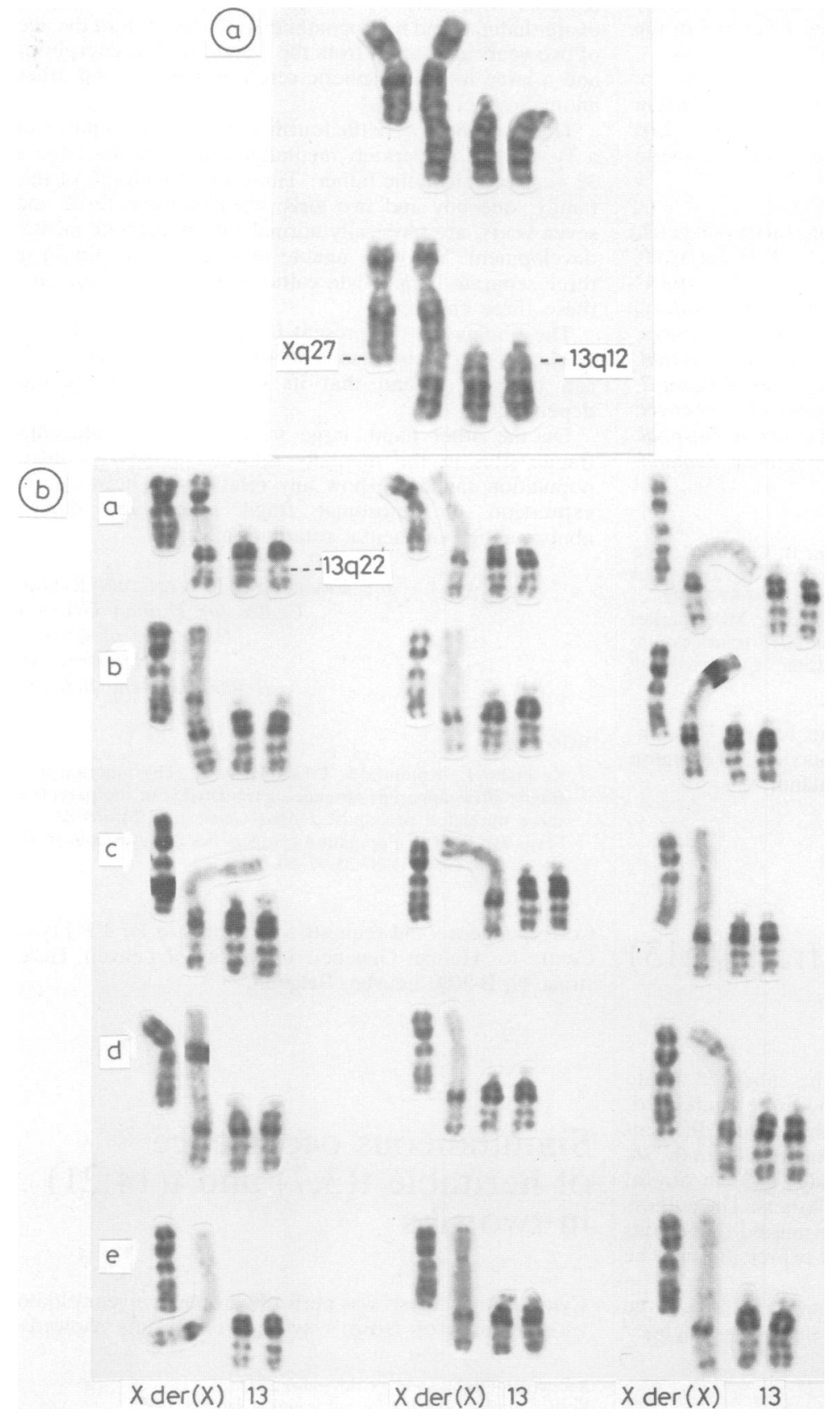

FIG 2 (a) GTG banded partial karyotypes from index case. Broken dotted lines indicate breakpoints. (b) Partial karyotypes from index case showing BrdU late replicating pattern in the $X, \operatorname{der}(X)$ and $13 \mathrm{~s}$. Note faint staining in a to $e$ of band 13q22. In other metaphases band $13 q 22$ is hardly visible. 
of late replication. In the $13 q$ portion of the $\operatorname{der}(\mathrm{X})$, band $13 q 22$ shows faint staining, suggesting late replication and hence inactivation. The phenotype of our patient supports the replication pattern in that she has some but not all the features associated with trisomy $13 q .{ }^{1}$

A $50 \%$ increase in her ESD activity, compared to that of the normal parents, confirms, as previously shown by Mohandas et $a l^{2}$ non-inactivation of the ESD loci in the $13 q$ portion of the $\operatorname{der}(\mathrm{X})$ chromosome.

We thank Dr R C Sparkes and colleagues of the Division of Medical Genetics, UCLA School of Medicine, Los Angeles for performing the ESD levels and Mrs $\mathrm{H}$ Lawton for typing the manuscript.

D R Romain*, L M Columbano-Green*, R G Parfitt*, R H SMYTHE*, N G MacKenzie $\dagger$, and C J Chapman* ${ }^{*}$ Cytogenetics Laboratory, Laboratory Services, Wellington Public Hospital, Wellington 2; and + Department of Pediatrics, Wanganui Hospital, Wanganui, New Zealand.

\footnotetext{
References

1 Rivas F, Rivera H, Plascencia ML, Ibarra B, Cantú JM. The phenotype in partial $13 q$ trisomies, apropos of a familial (13;15)(q22;q26) translocation. Hum Genet 1984;67:86-93.

2 Mohandas T, Crandall BF, Sparkes RS, Passage MB, Sparkes MC. Late replication studies in a human $X / 13$ translocation: correlation with autosomal gene expression. Cytogenet Cell Genet 1981;29:215-20.
}

Correspondence and requests for reprints to $\mathbf{D} \mathbf{R}$ Romain, Cytogenetics Laboratory, Laboratory Services, Wellington Public Hospital, Wellington 2, New Zealand.

\section{Is the expression of $\operatorname{fra}(2)(\mathrm{q} 13)$ age dependent?}

In 1987 Keskiaho et al described the inherited folate sensitive fragile site $\operatorname{fra}(2)(q 13)$ in three unrelated, mentally retarded children, two of them with different forms of epilepsy. Repeated chromosome studies in the six parents failed to detect the same fra(2)(q13) in any of them, except for one cell in one of the fathers. The authors concluded that fra $(2)(\mathrm{q} 13)$ can be transmitted by persons not expressing it and that fra(2)(q13) expression may be age dependent

In the fragile $X$ screening programme of the Leuven Centre for Human Genetics we had a similar experience. ${ }^{2}$

Received for publication 23 December 1987. Accepted for publication 8 January 1988 .
We detected a fra(2)(q13) in two dystrophic and $\overline{\bar{\omega}}$ profoundly retarded male sibs in $30 \%$ and $20 \%$ respectively of the cells in three different cultures. The boys were three months and 18 months old at the time of examination and presented with recurrent convulsions, failure to thrive, and similar dysmorphic craniofacial features with narrow, sloping forehead, long occiput, \& exophthalmia, and micrognathia. Both died before the age of two years and, apart from the craniofacial dysmorphism and a large interhemispheric cerebral hygroma, no other anomalies were found.

These brothers were the fourth and fifth born children of a 34 year old moderately mentally retarded mother and a 32 year old alcoholic father. Three other children of this is family, one boy and two girls, aged between three and seven years, are physically normal with borderline mental development. We were unable to find the $\operatorname{fra}(2)(\mathrm{q} 13)$ in three separate lymphocyte cultures from the parents and these three children.

The findings in the present family confirm the data of Keskiaho et $\mathrm{l}^{1}$ that persons not expressing the fra(2)(q13) can transmit it and that its expression may be age dependent.

On the other hand, large scale studies of autosomal fragile sites in the mentally retarded versus a control population failed to show any relationship between the expression of autosomal fragile sites and clinical abnormalities or mental retardation.

J P Fryns and H VAN den Berghe Centre for Human Genetics, University of Leuven, Herestraat 49 , B-3000 Leuven, Belgium.

\section{References}

1 Keskiaho L, Knuutila S, Pihko $\mathrm{H}$, et al. The inheritance of fragile sites: apparent absence of $\operatorname{fra}(2)(\mathrm{q} 13)$ in the parents of three unrelated probands. J Med Genet 1987;24:678-83.

2 Fryns JP, Petit P. Population cytogenetics of autosomal fragile sites. Clin Genet 1987;35:47-50.

Correspondence and requests for reprints to Dr J P Fryns, Centre for Human Genetics, University of Leuven, Herestraat 49 , B-3000 Leuven, Belgium.

\section{Simultaneous occurrence of heritable $t(3 ; 7)$ and $t(14 ; 21)$ in two sibs}

Cytogenetic analysis was performed on a one year old boy with features of Down's syndrome. Results showed a

Received for publication 18 November 1987

Revised version accepted for publication 4 January 1988. 